\title{
Tolerating Ambiguity: Leadership Lessons from Off-Road Motorcycling
}

\section{Author: Kenning Arlitsch}

This is a preprint of an article that originally appeared in Journal of Library Administration on January 2016.

Tolerating Ambiguity: Leadership Lessons from Off-Road Motorcycling Kenning Arlitsch Journal of Library Administration Vol. 56, Iss. 1, 2016.

doi: 10.1080/01930826.2015.1113063

Made available through Montana State University's $\underline{\text { ScholarWorks }}$ 
Column Title: posIT

Column Editor: Kenning Arlitsch, Dean of the Library, Montana State University, Bozeman, MT kenning.arlitsch@montana.edu

This JLA column posits that academic libraries and their services are dominated by information technologies, and that the success of librarians and professional staff is contingent on their ability to thrive in this technology-rich environment. The column will appear in odd-numbered issues of the journal, and will delve into all aspects of library-related information technologies and knowledge management used to connect users to information resources, including data preparation, discovery, delivery and preservation. Prospective authors are invited to submit articles for this column to the editor at kenning.arlitsch@montana.edu

\title{
Tolerating Ambiguity: Leadership Lessons from Off-Road Motorcycling
}

\author{
KENNING ARLITSCH \\ Dean of the Library, Montana State University, Bozeman, MT USA
}

\begin{abstract}
The ability to tolerate ambiguity is an important attribute of successful leaders. In this article the metaphor of off-road motorcycling is used to introduce the concept of ambiguity and the virtues of becoming tolerant and comfortable with the uncertainty that has become a hallmark of information age organizations. Tolerance of Ambiguity is a known leadership concept that also extends to employees. Many employees want to be involved earlier in the planning and decision making process of the organization, but may be uncomfortable with the ambiguity characteristic of early stage planning.
\end{abstract}

\section{Keywords}

Library administration; leadership; Tolerance of Ambiguity; motorcycling; organizational development.

\section{Introduction}

Motorcycles turn by leaning. Turning a motorcycle at speed extends the rider's body away from the bike and its center of weight, creating a lean angle made possible by grace of traction produced by rubber on asphalt. Tire materials and construction, suspension and frame geometries have become so advanced in the last few decades 
that a motorcycle rider on pavement can be confident in the certainty created by that traction. But not all roads are paved. Riding on dirt is different simply because the traction of the asphalt is absent. A rider leaning too hard into a turn on dirt may suddenly find the motorcycle sliding out from under him. In addition to turning, other actions relying on traction - accelerating, stopping, swerving to avoid obstacles - are compromised in the absence of pavement. Dirt has different forms, including gravel, sand and mud, and sometimes the "road" is marred with bumps and gullies. In short, the surface is loose and lacks uniformity. Riding on dirt is a dance with the machine, and relaxing into the ambiguity of the dance is key to staying upright. Another way to think about it? Holding on too tightly can end badly.

What, you are thinking, does any of this have to do with leadership in libraries?

Ours is a profession that has seen its share of uncertainty. Over the past couple decades, we have found our work dramatically impacted by technological developments that we did not always understand and by economic forces over which we have had little control. The technologies of the Internet demanded changes to our skills and work processes, and required that our services be unbound by time and place. Those same technologies created exciting new ways of reaching consumers and of helping fulfill our education and research missions. The contradictions of threat and possibility appeared while we watched the costs of our goods skyrocket and relative funding decline. Higher education across the nation suffered similar economic maladies as demand for services changed, as regulations and compliance costs increased, and as political winds demanded return on investment even as research funding and state support decreased.

These changes created ambiguity in a once stable profession. Uncertainty can induce fear, causing us to hunker down, shudder with every bump, and hold on more tightly to what we think we know.

\section{Riding}

Motorcycling is a physically engaging experience. The clutch is operated with the left hand, while the front brake and throttle are on the right. The left foot indexes through the gears and the right presses down to activate the rear brake. Coordinating all four limbs while leaning through curves and accounting for obstacles has a way of focusing the mind, shutting out everything else.

My more experienced friends compared riding a motorcycle on dirt to skiing. There is only the loosest relationship that keeps skis on snow and tires (even knobby tires) on dirt. It's a profoundly disturbing feeling, at first, this sense that the bike has only a passing connection with pebbles or sand as it more or less skates across the surface. The relationship is not one that breeds trust or comfort. But relaxing and becoming comfortable with this ambiguous situation is the only thing that can help make the ride safe and enjoyable. 
I've been a rider for over twenty years, but my experience with dirt only began in 2014 when I bought a bike built for that purpose. In that year I rode nearly 800 miles off pavement, including a trip to the north rim of the Grand Canyon, but I never felt comfortable. I knew that I lacked the skills to handle the bike on dirt, so I did what anyone who works in the education field would do: I signed up for a class.

In July I rode from Bozeman, MT to an off-road motorcycling school in Colorado, called Rawhyde. Established by Jim Hyde in 2002, Rawhyde's mission is to build supplemental skills to make riding off pavement safer and more enjoyable. Rawhyde is not a dirt bike or motocross school. It's aimed at those who ride big adventure bikes, like the kind popularized by Ewan McGregor and Charley Boorman in their travel documentaries (Alexanian, 2005). The activity has a longer history, dating to Helge Pederson as he traveled solo around the world over ten years on a BMW in the 1980's (Pedersen, Payne, \& Squire, 1998), or even further back to Ted Simon, who traveled through 45 countries on a Triumph in the 1970's (Simon, 1980). Modern adventure bikes often weigh over 500 pounds and are designed to carry a rider plus the gear he/she needs for lengthy trips on what the Germans call "Gelände/Strasse" (cross-country/street). "GS" has become the shorthand designation for this type of bike.

The two-day course at Rawhyde consisted of a variety of maneuvers at speeds so low there was often little besides the idle of the engine and feathering of the clutch to maintain forward movement. One might think the basic maneuvers would bore experienced riders, but they were surprisingly difficult at such low speed. We stood on our foot pegs nearly all the time, as is recommended for balance and control while riding on dirt.

The first thing we learned to do was to pick up the heavy bikes as they lay on the ground, because there was every expectation that we would fall. Then we practiced accelerating and stopping, completely at first and then graduating to "trail stops," where we braked to a standstill, shifted down and then accelerated again, all without putting a foot down. We swung a leg over the saddle while riding and balanced all our weight on the the left side of the bike and then the right, weaved through cones at idle speed, practiced braking hard, first with the front brake, then intentionally skidding with the rear, then both brakes simultaneously for maximum stopping force. We learned to shift our body weight forward while accelerating and back while braking. We rode up progressively steep hills with loose gravel, stopping and starting on both the incline and decline. In one particularly vexing exercise we conducted tight figure eight turns at idle speed and found that nearly every one of us had a mental block when it came to turning in one direction. For me it was turning to the right; it just did not work as smoothly as turning to the left.

The point of all this was to practice balance and control, and to see how the bikes behaved at speeds low enough that there was little fear of the inevitable falls. In another exercise we learned the proper technique for turning the bike at higher

(C) Kenning Arlitsch

Address correspondence to Kenning Arlitsch, Dean of the Library, Montana State University,

P.O. Box 173320, Bozeman, MT 59717-3320, USA. E-mail: kenning.arlitsch@montana.edu 
speeds on dirt, which is nearly opposite the technique used to turn on pavement. Instead of leaning with bike, turning on dirt requires maintaining weight over the wheels. The rider leans the bike toward the inside radius of the turn and and keeps his/her body straight above the wheels. It's an odd-looking and non-intuitive maneuver that involves turning the outside foot inward on the peg, pushing a knee into the gas tank, and leaning the bike away while maintaining nearly all body weight on the outside peg.

Even before we got out on the range we had spent an hour or two in the "classroom," (which doubles as Rawhyde's dining hall) where the instructors tried to impress upon us the importance of relaxing. With an instructor astride a bike parked on its center stand they simulated what would happen if a rider was holding tightly to the handlebars when the front wheel struck an obstacle. The force of the obstacle in this simulation was delivered by another trainer kicking the wheel. When the handlebar spun from the force of the kick the instructor's entire body turned with the front wheel and the implication was obvious - if he were holding on that tightly when the wheel turned during a ride he was almost certainly coming off the bike. On the other hand, a light touch on the handlebars allowed the wheel to momentarily go astray, but the recovery was much easier because the rider lost no balance.

On the range the instructors would admonish us to keep our heads up, to look into the middle distance. They wanted us to forget about the immediate foreground, to stop getting distracted by the small obstacles on which it is so easy to fixate. The "head up"concept will be familiar to those who have had leadership training.

After training sessions, the instructors would take us on hour-long rides where we would follow dirt roads and paths across ranch fields, practicing our newfound skills at higher speeds. It was during one of these rides that I had an epiphany. My skills were beginning to coalesce and I was feeling more comfortable about the phenomenon that I had begun thinking of as the "dance" between the bike, the earth and me. The instructors' admonition about relaxing began to sink in. The lateral movement of the bike underneath me was a distance that sometimes felt like a hairraising foot, but which in reality was probably only a few inches and I realized that this ambiguity was okay. The machine wants to track straight, and by some physics miracle of two inline spinning wheels and an amazingly engineered suspension it always managed to get back on track, even after the front wheel momentarily, and frighteningly, swam in deep sand or dived into holes or rolled over rocks. I felt my muscles loosen and I stopped fixating on the ground in front of my wheel and began looking ahead.

\section{Ambiguity Tolerance}

As I write this I have just completed the third year of my first position as a dean. Make no mistake, the job is exciting, challenging, and interesting in ways I could

(C) Kenning Arlitsch

Address correspondence to Kenning Arlitsch, Dean of the Library, Montana State University,

P.O. Box 173320, Bozeman, MT 59717-3320, USA. E-mail: kenning.arlitsch@montana.edu 
never have imagined. Professionally, it has been the best time of my life, but it's also stretched me into areas I would not previously have felt comfortable. Of the many lessons I've taken in the transition from an associate dean, learning to thrive amidst ambiguity looms large.

In academic terms, ambiguity is a situation that "cannot be adequately structured or categorized by the individual because of the lack of sufficient cues" (Budner, 1962). Budner described three situational types of ambiguity:

1. Novelty - a completely new situation in which there are no familiar cues;

2. Complexity - a complex situation in which there are a great number of cues to take into account;

3. Insolubility - a contradictory situation in which different elements or cues suggest different structures.

The ability of an individual to tolerate ambiguity has been a recognized leadership quality for more than fifty years (Frenkel-Brunswik, 1949). However, Klenke points out that most leadership literature "predates the information age," and warns that "leadership researchers have not taken into account the role of information technology (IT) as a salient component of the leadership situations" (Klenke, 1992). Others note that this new age has brought with it a relentless fire hose of information. "What is new, is the boundless scope and accelerated pace of human transactions, and the growing globalization of human interconnectedness" (Bandura, 2001). Most industries have been dramatically impacted by information technologies, and some have been radically changed or no longer exist. The library profession has fortunately survived thus far with alterations to the way business is conducted.

Tolerance of Ambiguity (ToA) is "the tendency to perceive ambiguous situations as desirable," and conversely, the intolerance of ambiguity is "the tendency to perceive ambiguous situations as sources of threat" (Budner, 1962). ToA doesn't appear to have been addressed directly in the library administration literature, but it has appeared in the related discipline of Knowledge Management, where "low ToA individuals tend to either react negatively or simplify the decision making scenario by ignoring the ambiguity-causing cue" (Iyer \& Ravindran, 2009). It's also wellrecognized in the business world. "Tolerance for ambiguity is an attribute that is increasing in value as the world grows smaller and globalization influences the business sector" (Huber, 2003). Because there are few prescribed responses to ambiguous situations, decisions are often made by intuition, "a skill that has been portrayed as everything from a magical sixth sense to an innate personality trait to an accumulation of experience" (Burke \& Miller, 1999).

Shared governance and consensus based decision-making have long been hallmarks of academic libraries, but recent years have seen a further diminishing of hierarchical management, reflecting changes that have occurred in many high tech industries and the expectations of the millennial generation (Downing, 2006). A

(C) Kenning Arlitsch

Address correspondence to Kenning Arlitsch, Dean of the Library, Montana State University,

P.O. Box 173320, Bozeman, MT 59717-3320, USA. E-mail: kenning.arlitsch@montana.edu 
concomitant desire for more adhocracy in academic libraries (Maloney, Antelman, Arlitsch, \& Butler, 2010) has ramifications for leaders. "As organizational structures become less hierarchical and more fluid and amorphous, tolerance for ambiguity and uncertainty is likely to emerge as a quality that differentiates effective from ineffective leaders. Leader behaviors critical for survival in contemporary organizations...are best achieved by people who have a tolerance for ambiguity and uncertainty"'” (Lane \& Klenke, 2004). Employees also are concerned with whether their leaders can handle ambiguity. "Generalized beliefs about leadership are significantly related to employees' perceptions that their leader is able to reconcile conflicting demands, tolerate uncertainty, exercise foresight, and create a cohesive organization" (Ehrlich, Meindl, \& Viellieu, 1990). The ability to tolerate ambiguity, therefore, is a desirable leadership trait.

It can be difficult to develop compelling visions and long-term plans while facing continuing changes in the profession. It makes one feel as though there is not much traction underfoot. As I've wrestled with decisions for the organization, its employees and the constituents we serve I've come to realize that ToA is not only desirable in leaders. Employees throughout organizations must deal with ambiguity on a daily basis as well, in part due to changes in the profession that directly affect their work, but also because of the uncertain effects of management decisions that can make them feel they lack control of their own destinies. Bandura notes that "the capacity to exercise some measure of control over the nature and quality of one's life is the essence of humanness," (Bandura, 2001). The excessive amount of information that we are all forced to deal with is daunting, as are the relentless decisions waiting to be made on that information. Employees who are unable to develop a tolerance for ambiguity may grow fearful and become entrenched, choosing to hold on tightly to what they understand rather than reconcile with uncertainty.

A particular sweet spot that I have yet to find is the right time to communicate new ideas, plans or policy changes to faculty and staff. Some time ago we consolidated some of the organizational structure and I thought I had done a good job planning the change with my leadership team and then discussing it with the affected parties quickly and sequentially to avoid rumors. But I was later taken to task in an all-staff meeting for not having involved more of the organization earlier. Lesson learned. The next time I had an idea for a significant change I brought it to the faculty and staff much sooner. But a funny thing happened. People wanted details about how this new change might work. I told them I didn't know because the idea was still in early stages, and that I wanted them to help me figure it out. This, I discerned almost immediately, created great discomfort. Something was maybe going to happen, but the who, what, how, and when was far from clear and that caused consternation and nervousness.

An attribute of an ambiguity tolerant leader is being able to "feather" the pace of the organization - maneuvering at a slower or faster rate in accordance with the challenges or obstacles. Gaining feedback from faculty and staff is critical to

(C) Kenning Arlitsch

Address correspondence to Kenning Arlitsch, Dean of the Library, Montana State University,

P.O. Box 173320, Bozeman, MT 59717-3320, USA. E-mail: kenning.arlitsch@montana.edu 
fostering a communicative environment that will hopefully build trust and ToA. Employees want to know about potential changes early and want the opportunity to provide input, but it is clear that not everyone is comfortable working with halfbaked ideas. Some may want every detail determined before they feel comfortable moving forward and it may be necessary to slow down the process or even stop and approach from a new angle. In other words, more adhocracy may be desired in theory but that may mean more ambiguity that some find difficult to tolerate. ToA is an attribute that I will be looking for in my new hires.

\section{Summary}

There is no universal formula to help people become comfortable with ambiguity. How we react to our environments is driven largely by personality, past experience and ability to trust. But awareness can help and some discoveries can help the concept of ToA resonate on a personal level. The metaphor of the motorcycle is not for everyone, but for me it illustrated the dance of balance and control over unstable terrain, and thus helped me cogitate on my previously vague understanding of ambiguity tolerance. Of course, the overall concept of ToA isn't anything new. A relaxed and "centered" approach is ubiquitous in religion, philosophy, sport, and the practices of meditation and mindfulness. Our best performance in almost any field occurs when we are relaxed.

The ability of the leader to tolerate ambiguity is not unlike the motorcycle rider being comfortable with the uncertainty of riding on dirt. The loose relationship of the bike to the ground can be frightening, but as a finely engineered machine the motorcycle requires only a light touch to keep it upright and moving forward. An organization could likewise be considered a finely engineered machine by virtue of its employees, competent professionals who know how to do their jobs and who work in concert to keep the organization moving forward. Holding on tightly to the motorcycle as it begins to sidle is instinctive but counter-effective, just as insisting on more than a light touch in the organization can be detrimental. Understanding the strengths of the machine and positioning it for maximum impact and success is the light touch that is required from a leader. This is where the dance between the organization and the ever changing technological landscape becomes cooperative and fluid.

\section{References}

Alexanian, D. (2005). Long Way Round [DVD video] (Vols. 1-3). S.I.

Bandura, A. (2001). The changing face of psychology at the dawning of a globalization era. Canadian Psychology/Psychologie Canadienne, 42(1), 1224. http://doi.org/10.1037/h0086876

Budner, S. (1962). Intolerance of ambiguity as a personality variable. Journal of Personality, 30(1), 29. 
Burke, L. A., \& Miller, M. K. (1999). Taking the mystery out of intuitive decision making. The Academy of Management Executive, 13(4), 91-99.

Downing, K. (2006). Next generation: What leaders need to know about the millennials. Leadership in Action, 26(3), 3-6. http://doi.org/10.1002/lia.1161

Ehrlich, S. B., Meindl, J. R., \& Viellieu, B. (1990). The charismatic appeal of a transformational leader: An empirical case study of a small, high-technology contractor. The Leadership Quarterly, 1(4), 229-247. http://doi.org/10.1016/1048-9843(90)90003-Z

Frenkel-Brunswik, E. (1949). Intolerance of ambiguity as an emotional and perceptual personality variable. Journal of Personality, 18(1), 108-143.

Huber, N. (2003). An Experiential Leadership Approach for Teaching Tolerance for Ambiguity. Journal of Education for Business, 79(1), 52-55.

Iyer, G. S., \& Ravindran, S. (2009). Usefulness, incentives and knowledge management. Journal of Knowledge Management, 13(6), 410-430. http://doi.org/10.1108/13673270910997097

Klenke, K. (1992). Leadership Processes in Computer Mediated Work Groups: Implications of Information Systems Development and Leadership Studies. In K. E. Kendall (Ed.), The impact of computer supported technologies on information systems development (pp. 115-132). North Holland: Elsevier Science Publishers B.V.

Lane, M. S., \& Klenke, K. (2004). The Ambiguity Tolerance Interface: A Modified Social Cognitive Model for Leading Under Uncertainty. Journal of Leadership \&amp; Organizational Studies, 10(3), 69-81. http://doi.org/10.1177/107179190401000306

Maloney, K., Antelman, K., Arlitsch, K., \& Butler, J. (2010). Future Leaders' Views on Organizational Culture. College \& Research Libraries, 71(4), 322-347. http://doi.org/10.5860/crl-47

Pedersen, H., Payne, D., \& Squire, S. (1998). 10 years on 2 wheels: 77 countries, 250,000 miles. Seattle, Wash.: Elfin Cove Press.

Simon, T. (1980). Jupiter's travels (1st ed. in the U.S.A). Garden City, N.Y: Doubleday. 